\title{
The impact of challenge-hindrance stressors on creativity: the mediating role of regulatory focus and the moderating role of proactive personality
}

\author{
Yixin Yang ${ }^{1}$ and Mingjian Zhou $^{2}$ \\ ${ }^{1}$ School of Economics and Management, Harbin Institute of Technology, Shenzhen, Guangdong, 518000, China \\ ${ }^{2}$ School of Economics and Management, Harbin Institute of Technology, Shenzhen, Guangdong, 518000, China
}

\begin{abstract}
Based on the challenge-hindrance stressors framework and regulatory focus theory, this study explored the mediating role of promotion focus between challenge stressors and employee creativity, and the mediating role of prevention focus between hindrance stressors and creativity. In addition, we further explored the moderating role of proactive personality in this model. In the end, we discuss implications and limitations of our argument for theory and practices.
\end{abstract}

\section{Introduction}

With the rapid development of economy, innovation has become a key factor for organizations to gain competitive advantage and survive in the fierce market competition. As the main force of enterprise innovation activities, employee creativity is the basis of innovation and development for enterprises[1-2]. However, works with high demand and fast pace make employees face heavy job stress, which will cause some psychological problems such as emotional exhaustion and job burnout, and then affect the creativity of employees. Therefore, how to improve employee creativity under heavy job stress has become a hot topic for managers and scholars.

Many scholars have studied the relationship between stressors and employee creativity since Cavanaugh et al.(2000) classified stressors into two categories: challenge stressor and hindrance stressor[3]. However, there are inconsistent results among these researches. Hindrance stressors have been shown to weaken creativity, while the results of challenge stressors are inconsistent[4]. Meanwhile, the mechanism through which stressors affect employee creativity has not been discussed by scholars in depth. Inconsistent conclusions and unclear influence mechanism hinder the development of theories, which means that we cannot suggest managers about how to promote the employee creativity.

Based on previous researches, this study will construct a mechanism model about the impact of job stressors (challenge stressor and hindrance stressor) on employee creativity. There are three purposes: firstly, investigate how job stressors induce different types of regulatory focus; secondly, clarify the mediating role of regulatory focus between stressors and creativity; thirdly, explore the moderating role of proactive personality. The hypothesized model is shown in Figure 1.

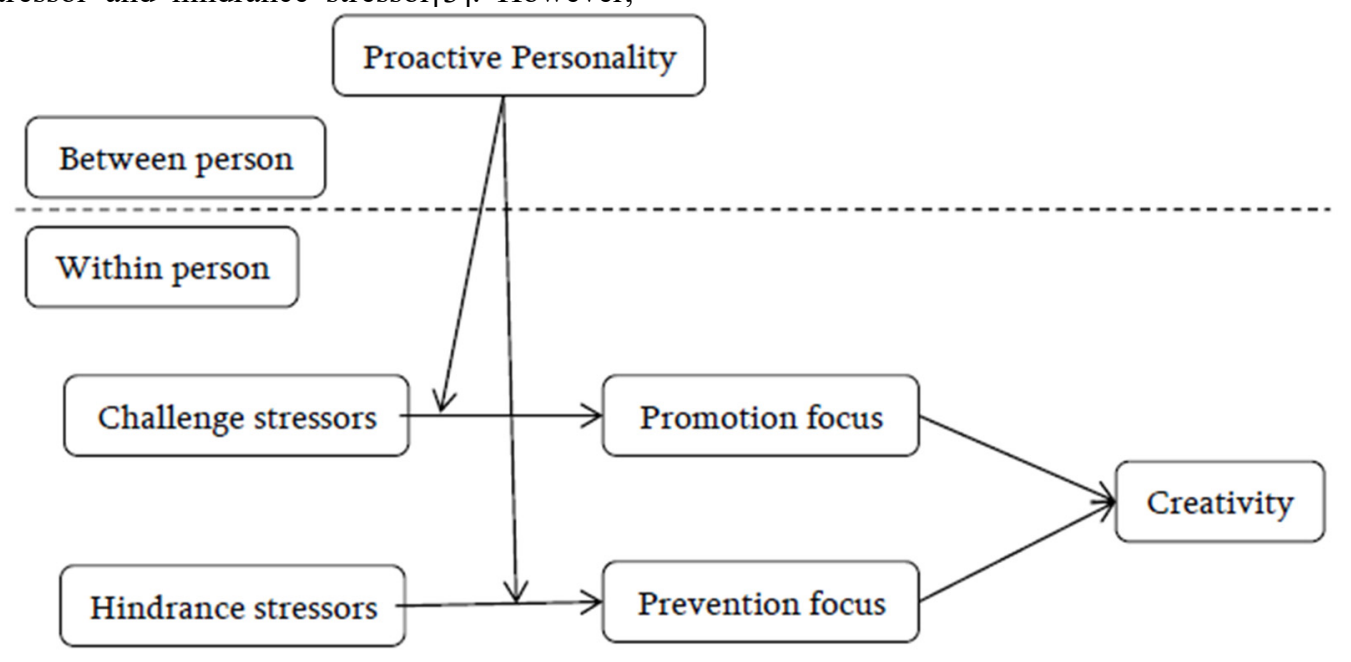

Figure 1 Hypothesized Model 


\section{Theoretical background and hypothesis development}

\subsection{The effect of challenge-hindrance stressors on creativity}

Based on the previous researches, Cavanaugh et al.(2000) put forward the concept of challenge-hindrance stressors[3]. Challenge stressors refer to the stresses that individuals think they can overcome, which have positive significance for their job performance and growth, such as workload, job scope, time pressure and job responsibility; Hindrance stressors refer to the stresses that individuals find difficult to overcome, which hinder the realization of their work goals, such as job insecurity, role ambiguity, and organizational politics[5]. Although challenge stressors can bring stresses, individuals believe that they will gain benefits and rewards in terms of job performance and promotion once they overcome, then adopt positive coping strategies. However, individuals think that the stresses brought by hindrance stressors will not bring any benefits and returns but hinder their career development, and then take negative coping strategies[6-7].

Creativity refers to innovative and practical ideas of employees for products, services and processes[8]. Based on the distinction of stressors, this study believes that there are differences in the impact of challenge stressors and hindrance stressors on employee creativity. Firstly, based on Expectancy Theory, as overcoming challenge stressors can improve job performance, employees will make positive expectations and coping strategies, in which subjective initiative and innovative ideas will easily generate; while overcoming hindrance stressors is not conductive to career development, employees will make negative expectations and coping strategies, in which new ideas will difficultly generate. Secondly, according to Conservation of Resources Theory, individuals are willing to invest resources in activities with low risk or high return to increase their own resource stock[9]. Coping with challenge stressors, employees can obtain potential benefits while consuming resources (such as energy and time), so positive investment of resource is conducive to producing creative results; while overcoming hindrance stressors not only consumes resources, but also brings no return for employees, so they will not take risks to invest resources to deal with hindrance stressors and then hinder the generation of creative behaviors.

Previous studies have shown that challenge stressors play a positive role in job performance, job attitudes, and personal well-being, while hindrance stressors suppress these positive perceptions and behaviors[5,10]. In addition, Hong et al.(2013) took hotel employees and their direct supervisors as the research objects, and found that challenge stressors had a significant positive impact on employee creativity, while hindrance stressors had a significant negative impact on employee creativity[11]. Mehta and Zhu(2016) also found a positive association between time pressure(challenge stressor) and creativity[12]. Thus, we hypothesize that:

H1a: Challenge stressors have a significant positive impact on employee creativity.

H1b: Hindrance stressors have a significant positive impact on employee creativity.

\subsection{The mediating role of regulatory focus}

Higgins(1997) put forward the regulatory focus theory, which describes the difference of individual behavior due to different regulatory foci[13]. Regulatory focus is often used as a stable personality trait to explain employees' attitudes and behaviors. In fact, regulatory focus can also be an immediate psychological state that is stimulated by situational factors, which is called situational regulatory focus[14]. Promotion focus is a motivational condition that is sensitive to and regulates around the positive outcomes such as hope, development and success, which helps individuals meet their needs of growth and tend to use approach strategies to achieve goals[4,15]. In contrast, prevention focus is a motivational condition that is sensitive to and regulates around the negative outcomes such as obligations, responsibilities and safety, which helps individuals meet their needs of security and tend to pursue goals with avoidance strategies $[4,16]$.

Based on the regulatory focus theory and the framework of challenge-hindrance stressors, this study considers that challenge stressors and hindrance stressors can induce different regulatory foci of employees. On the one hand, challenge stressors, as a situation emphasizing growth needs, achievement and benefits, can induce employees' promotion focus. Challenge stressors are considered that can bring opportunities for growth and development, which arouse employees' growth needs; and overcoming challenge stressors can obtain potential benefits and meet their achievement needs[4]. So, employees tend to adopt aggressive strategies to gain opportunities for growth and development in the face of challenge stressors, thus leading to the promotion focus. On the other hand, hindrance stressors, as a situation emphasizing security needs, responsibility fulfillment and possible loss, can trigger employees' prevention focus[15-16]. Hindrance stressors are often related to job demands such as role conflict, organizational politics and job insecurity, which may hinder the realization of job goals and career development and bring losses or injuries, then forcing employees to only fulfill the minimum work obligations[6-7,17]. So, employees often adopt avoidance strategies to avoid losses or failure in the face of hindrance stressors, thus inducing prevention focus[15-16]. Thus, we hypothesize that:

H2a: Challenge stressors have a significant positive impact on promotion focus.

$\mathrm{H} 2 \mathrm{~b}$ : Hindrance stressors have a significant positive impact on prevention focus.

Based on the regulatory focus theory, this study argues that promotion focus and prevention focus have different effects on employee creativity. Promotion focus has a positive impact on creativity. Promotion focus means an approach motivation, which tends to use 
aggressive strategies to achieve goals[18]. On the one hand, employees with promotion focus have strong positive internal motivation such as growth, development and self-realization[19]; on the other hand, they will show creative thinking and actively try various solutions to problems when facing risks and challenges[20]. Thus, challenge stressors can induce employees' promotion focus, which encourages them to show higher intrinsic motivation and innovative thinking, and then improve their creativity. Prevention focus has a negative impact on creativity. Prevention focus means an avoidance motivation, which tends to use evasive strategies to pursue goals[18]. On the one hand, employees with prevention focus are mainly driven by extrinsic motivations such as safety, security and obligation, and have a low level of intrinsic motivation[19]; on the other hand, they usually show risk aversion and adopt avoidance attitude to avoid loss and failure, and they show conservative tendency and are unwilling to try new methods and new thinking in solving problems[20]. Thus, hindrance stressors can induce employees' prevention focus, which reduces their intrinsic motivation and creative thinking, and then inhibit their creativity. Thus, we hypothesize that:

H3a: Promotion focus mediates the relationship between challenge stressors and employee creativity. In other words, promotion focus can enhance the positive impact of challenge stressors on employee creativity.

H3b: Prevention focus mediates the relationship between hindrance stressors and employee creativity. In other words, prevention focus can enhance the negative impact of hindrance stressors on employee creativity.

\subsection{The moderating role of proactive personality}

Proactive personality is a tendency of individuals to take some active actions and thus influence the external environment[21]. Individuals with high level of proactive personality are better at finding opportunities from the complex external situation and take more active behaviors to adapt and change the external environment. As a tendency of facing the future and change, proactive personality is an important personality antecedent of creativity in organizational context. Individuals with high-level proactive personality have relatively stable tendency to challenge the status quo and introduce change initiatively; they also tend to seek opportunities and develop innovative ideas for completing tasks[22]. Therefore, this study considers that proactive personality can moderate the relationship between challengehindrance stressors and regulatory focus.

On the one hand, proactive personality can enhance the positive effect of challenge stressors on promotion focus. Faced with challenge stressors, employees with high-level proactive personality will actively identify the opportunities of growth and development brought about by challenge stressors, and persevere in finding solutions to overcome difficulty, which is beneficial for them[2324]. At the same time, proactive personality can enhance employees' positive interpretation of challenge stressors and positive attitude of "stress-promotion", which will strengthen the situational activation of challenge stressors on growth needs and potential benefits, and then induce a higher level of promotion focus. In contrast, employees with low-level proactive personality prefer to maintain the status quo rather than take risks to meet additional challenges or development opportunities[25]. So it is difficult for them to identify growth opportunities and generate positive interpretations, thus inducing a lower level of promotion focus.

On the other hand, proactive personality can weaken the positive effect of hindrance stressors on prevention focus. Hindrance stressors can bring potential loss and injury to employees, and hinder the realization of work goals and career development. Faced with hindrance stressors, employees with low-level proactive personality tend to follow the established process and are not prepared for change. These passive behaviors will induce a higher level of prevention focus [26-27]. At the same time, employees with low-level proactive personality show negative interpretation of hindrance stressors and form the negative attitude of "stress-weakening", which will situational activation of hindrance stressors on safety needs and potential loss, and then induce a higher level of prevention focus. In contrast, employees with highlevel proactive personality will weaken the negative interpretation of hindrance stressors and actively overcome difficulties, thus reducing the possibility of prevention focus to a certain extent. Thus, we hypothesize that:

$\mathrm{H} 4 \mathrm{a}$ : Proactive personality positively moderates the relationship between challenge stressors and promotion focus. In other words, high-level proactive personality will enhance the positive influence of challenge stressors on promotion focus.

H4b: Proactive personality negatively moderates the relationship between hindrance stressors and prevention focus. In other words, high-level proactive personality will weaken the positive influence of hindrance stressors on prevention focus.

\section{Discussion}

\subsection{Implication}

This study has some contributions to the literature. Firstly, this study enriches the researches of exploring the relationship between challenge-hindrance stressors and creativity, we consider the mediating role of regulatory focus and the moderating role of proactive personality in this model and explain the influence mechanism between stressors and creativity. Secondly, this study expands the antecedents of regulatory focus theory, the challenge-hindrance stressors framework is introduced into the antecedents of the regulatory focus to explore how different types of stressors induce different regulatory foci.

This study also has some practical implications on how to improve employee creativity. Challenge stressors can improve creativity by inducing promotion focus, while hindrance stressors can reduce reativity by inducing prevention focus. On the one hand, managers 
can appropriately increase the challenge job demands and reduce the hindrance job demands to improve employee creativity; on the other hand, managers can guide employees to pay more attention to the opportunities and potential benefits brought by stresses and help employees form positive and proactive attitude, so as to induce the promotion focus and improve employee creativity.

\subsection{Limitation}

Several limitations in this research should be acknowledged. Firstly, we only explore the impact of stressors on employee creativity at individual level, without considering team-level factors, such as leadership style and team climate. Researches in the future can explore the impact of these factors on the relationship between stressors and creativity. Secondly, our proposed model is limited because it cannot apply to all samples and there are always exceptions. In addition, we just put forward a theoretical model which locks data support, we can apply practical research to test and verify the correction of this model in the future.

\section{Conclusion}

In this study, we construct a research framework of the impact of challenge-hindrance stressors on creativity. Based on regulatory focus theory, we explore how two different types of stressors affect employee creativity by stimulating their different regulatory foci, and further explore the role of proactive personality as a moderator. We believe that challenge stressors can improve employee creativity by inducing promotion focus, and proactive personality can enhance the positive effect of challenge stressors on creativity.

\section{Acknowledgments}

I would like to give my greatest gratitude to my supervisor Prof. Zhou, he has helped me develop a good study habit and given me a lot of guidance and advice. Also, I would like to thank my family for their support, they give me the greatest encouragement. I will try my best to do researches.

\section{References}

1. Liu, D., Gong, Y.P., Zhou, J., Huang, J.C. (2017) Human Resource Systems, Employee Creativity, and Firm Innovation: The Moderating Role of Firm Ownership. Academy of Management Journal, 60(3): 1164-1188.

2. Shao, Y., Nijstad, B.A., Tauber, S. (2019) Creativity under workload pressure and integrative complexity: The double-edged sword of paradoxical leadership. Organizational Behavior and Human Decision Processes, 155: 719.
3. Cavanaugh, M.A., Boswell, W.R., Roehling, M.V., Boudreau, J.W. (2000) An empirical examination of self-reported work stress among US managers. Journal of Applied Psychology, 85(1): 65-74.

4. Sacramento, C.A., Fay, D., West, M.A. (2013) Workplace duties or opportunities? Challenge stressors, regulatory focus, and creativity. Organizational Behavior and Human Decision Processes, 121(2): 141-157.

5. Rosen, C.C., Dimotakis, N., Cole, M.S., Taylor, S.G., Simon, L.S., Smith, T.A., Reina, C.S. (2020) When challenges hinder: An investigation of when and how challenge stressors impact employee outcomes. The Journal of Applied Psychology, 105(10): 1181-1206.

6. Wood, S.J., Michaelides, G. (2016) Challenge and hindrance stressors and wellbeing-based worknonwork interference: A diary study of portfolio workers. Human Relations, 69(1): 111-138.

7. Pearsall, M.J., Ellis, A.P.J., Stein, J.H. (2009) Coping with challenge and hindrance stressors in teams: Behavioral, cognitive, and affective outcomes. Organizational Behavior and Human Decision Processes, 109(1): 18-28.

8. Amabile, T.M., Conti, R., Coon, H., Lazenby, J., Herron, M. (1996) Assessing the work environment for creativity. Academy of Management Journal, 39(5): 1154-1184.

9. Hobfoll, S.E. (2001) The influence of culture, community, and the nested-self in the stress process: Advancing Conservation of Resources theory. Applied Psychology-an International Review-Psychologie Appliquee-Revue Internationale, 50(3): 337-370.

10. Zhang, Y.W., Zhang, Y., Ng, T.W.H., Lam, S.S.K. (2019) Promotion- and Prevention-Focused Coping: A Meta-Analytic Examination of Regulatory Strategies in the Work Stress Process. Journal of Applied Psychology, 104(10): 12961323.

11. Hon, A.H.Y., Chan, W.W.H., Lu, L. (2013) Overcoming work-related stress and promoting employee creativity in hotel industry: The role of task feedback from supervisor. International Journal of Hospitality Management, 33: 416-424.

12. Mehta, R., Zhu, M. (2016) Creating When You Have Less: The Impact of Resource Scarcity on Product Use Creativity. Journal of Consumer Research, 42(5): 767-782.

13. Higgins, E.T. (1997) Beyond pleasure and pain. American Psychologist, 52(12): 1280-1300.

14. Kark, R., Van Dijk, D. (2007) Motivation to lead, motivation to follow: The role of the selfregulatory focus in leadership processes. Academy of Management Review, 32(2): 500-528.

15. Neubert, M.J., Kacmar, K.M., Carlson, D.S., Chonko, L.B., Roberts, J.A. (2008) Regulatory 
Focus as a Mediator of the Influence of Initiating Structure and Servant Leadership on Employee Behavior. Journal of Applied Psychology, 93(6): 1220-1233.

16. Lanaj, K., Chang, C.H., Johnson, R.E. (2012) Regulatory Focus and Work-Related Outcomes: A Review and Meta-Analysis. Psychological Bulletin, 138(5): 998-1034.

17. LePine, M.A., Zhang, Y.W., Crawford, E.R., Rich, B.L. (2016) Turning Their Pain to Gain: Charismatic Leader Influence on Follower Stress Appraisal and Job Performance. Academy of Management Journal, 59(3): 1036-1059.

18. Ferris, D.L., Yan, M., Lim, V.K.G., Chen, Y.Y., Fatimah, S. (2016) An Approach-Avoidance Framework of Workplace Aggression. Academy of Management Journal, 59(5): 1777-1800.

19. Rhee, E.Y., Fiss, P.C. (2014) Framing Controversial Actions: Regulatory Focus, Source Credibility, and Stock Market Reaction to Poison Pill Adoption. Academy of Management Journal, 57(6): 1734-1758.

20. Johnson, P.D., Smith, M.B., Wallace, J.C., Hill, A.D., Baron, R.A. (2015) A Review of Multilevel Regulatory Focus in Organizations. Journal of Management, 41(5): 1501-1529.

21. Bateman, T.S., Crant, J.M. (1993) The Proactive Component of Organizational-Behavior - a Measure and Correlates. Journal of Organizational Behavior, 14(2): 103-118.

22. Li, F., Chen, T., Chen, N.Y., Bai, Y., Crant, J.M. (2020) Proactive yet reflective? materializing proactive personality into creativity through job reflective learning and activated positive affective states. Personnel Psychology, 73(3): 459-489.

23. Rodrigues, N., Rebelo, T. (2013) Incremental validity of proactive personality over the big five for predicting job performance of software engineers in an innovative context. Journal of Work and Organizational Psychology, 29(1): 2127.

24. Srikanth, P.B., Jomon, M.G. (2020) Developing managerial competencies: integrating work design characteristics and developmental challenge. International Journal of Human Resource Management, 31(22): 2808-2839.

25. Zhang, Z., Wang, M., Shi, J. (2012) Leaderfollower congruence in proactive personality and work outcomes: The mediating role of leadermember exchange. Academy of Management Journal, 55(1): 111-130.

26. Srikanth, P.B., Jomon, M.G., Thakur, M. (2020) Developmental idiosyncratic i-deals and its influence on promotability decisions: The joint roles of proactive personality and developmental challenge. The International Journal of Human Resource Management.
27. I - Heng (Ray) Wu, Nai - Wen Chi. (2020) The journey to leave: Understanding the roles of perceived ease of movement, proactive personality, and person-organization fit in overqualified employees' job searching process. Journal of Organizational Behavior, 41(9): 851870 . 